\title{
Density-dependent foraging in the sea urchin Centrostephanus rodgersii on shallow subtidal reefs in New South Wales, Australia
}

\author{
N. L. Andrew*, A. J. Underwood \\ Institute of Marine Ecology, Zoology Building, University of Sydney, NSW 2006, Australia
}

\begin{abstract}
An experimental manipulation of density in the diadematid sea urchin Centrostephanus rodgersii demonstrated that the species has a large impact on the abundance of large brown algae, limpets and crustose coralline algae. Significant non-linearities were observed in these variables in response to the removal of all, $66 \%, 33 \%$ or no sea urchins from naturally occurring patches of Barrens habitat in New South Wales. Removal of all sea urchins caused the loss of the Barrens habitat and the development of an assemblage of foliose algae. Foliose algae did not successfully colonize treatments in which only some sea urchins were removed. Partial removals caused reductions in the size of patches that were not linearly related to density. Changes in size of patches were interpreted as being a complex product of the size and shape of crevices containing sea urchins.
\end{abstract}

\section{INTRODUCTION}

The impact of grazing by sea urchins on shallow subtidal reefs varies in space and time. Some species, at some places and times, can have large impacts on habitat structure, while others have little influence (Ogden et al. 1973, Estes \& Palmisano 1974, Dayton 1975, Duggins 1980, Moreno \& Sutherland 1982, Santelices \& Ojeda 1984, Elner \& Vadas 1990, Watanabe \& Harrold 1991). Much of the evidence suggesting that sea urchins are important herbivores in tropical and temperate subtidal systems comes from experimental removals of sea urchins from reefs (e.g. Forster 1959, Kitching \& Ebling 1961, Vance 1979, Duggins 1980, Sammarco 1980, Chapman 1981, Sousa et al. 1981, Andrew \& Choat 1982, Cowen et al. 1982, Himmelman et al. 1983, Breitburg 1985, Hay \& Taylor 1985 , Fletcher 1987, Witman 1987).

On temperate rocky reefs, the effects of smaller changes in the local density of sea urchins are less well understood. Several studies (e.g. Mattison et al. 1977. Bernstein et al. 1981, Harrold \& Reed 1985, Tegner \&

\footnotetext{
- Present address: Fisheries Research Institute, New South Wales Fisheries, PO Box 21, Cronulla NSW 2230, Australia
}

Dayton 1991, Watanabe \& Harrold 1991) have described the consequences of changes in behaviour of sea urchins associated with natural changes in density and/or food availability. Such changes in behaviour often lead to the destruction or recolonization of kelp forests (op. cit.). Further, consequences to community structure have been inferred from experimental studies of changes in behaviour with respect to predators (e.g. Bernstein et al. 1981, Duggins 1983, Vadas et al. 1986, Scheibling \& Hamm 1991).

To our knowledge, however, the only experimental studies of the effects on habitat structure of grazing by sea urchins at different densities, beyond the presence/absence experiments cited above, are Ebert's (1977) study of Strongylocentrotus franciscanus and $S$. purpuratus and Valentine \& Heck's (1991) manipulations of Lytechinus variegatus densities in a seagrass meadow in Florida, USA. Both studies manipulated densities within enclosures and suffered problems in interpretation of results because of escapes (Ebert 1977 ) or apparent artefacts of the enclosures (Valentine \& Heck 1991).

The sea urchin Centrostephanus rodgersii (Agassiz) is the most important herbivore on subtidal reefs in New South Wales, Australia. Grazing by C. rodgersii 
and associated molluscan herbivores removes foliose algae from large areas of reefs (Fletcher 1987. Andrew \& Underwood 1989, Andrew 1991, 1993, Underwood et al. 1991). Removal of C. rodgersii causes an increase in the abundance of foliose algae and a concomitant reduction in the density of crustose algae and limpets (Fletcher 1987). The assemblage of foliose algae that develops when C. rodgersii is removed is not predictable. In Fletcher's experiments, the laminarian alga Ecklonia radiata recruited in large numbers to some replicates and canopy-forming forests developed. In other replicates, Sargassum spp. and articulated corallines dominated (Fletcher 1987).

In this paper, we describe an experimental manipulation to test whether the effects of grazing by Centrostephanus rodgersii were linearly related to density. Individual C. rodgersii remain in crevices during the day and emerge at night to forage before returning to the same crevice at dawn (Jones \& Andrew 1990). An effect of this reliance on day-time shelters is that discrete patches of Barrens habitat are often created. These patches provide natural units for experimentation; they have the added advantage of allowing manipulations of densities without restraining structures such as cages or fences.

\section{METHODS}

The experiment described here tested the effect of partial removal of adult Centrostephanus rodgersii on the abundance of algae and molluscan herbivores. Four densities of $C$. rodgersii were chosen: zero (Removal), $33 \%$ and $66 \%$ of original and a control (100\% of original). Treatments were replicated in 4 discrete patches of Barrens habitat, each between 3 and $4 \mathrm{~m}^{2}$ in area. Sixteen such patches were selected at Cape Banks, New South Wales, and treatments randomly assigned to patches. The crevices within these patches were comprised of either undercut platforms or boulders resting on the substratum. Patches used in the experiment were in water 2 to $5 \mathrm{~m}$ deep, separated by at least $5 \mathrm{~m}$ and spread over an area of approximately $2000 \mathrm{~m}^{2}$.

Densities of adult Centrostephanus rodgersii were reduced by removing randomly-chosen sea urchins until the number per patch reached the required percentage of the original density. There were no significant differences among treatments in the density of adult sea urchins prior to manipulation $\left(F_{[3,12)}=1.92\right.$, ns; mean density $=38.4 \pm 3.5, \pm \mathrm{SE}, \mathrm{n}=16$ pooled across treatments). Treatments were maintained whenever necessary and at least monthly by removing randomly selected sea urchins. The densities of $C$. rodgersii smaller than $50 \mathrm{~mm}$ test diameter (TD), other invertebrate herbivores such as limpets and topshells were not manipulated. There were no significant differences among treatments in the proportion of small sea urchins prior to manipulation $\left(F_{(3.12)}=1.26, \mathrm{~ns}\right)$. On average, sea urchins smaller than $50 \mathrm{~mm}$ TD made up $31.5 \%( \pm 3.44, n=16)$ of the populations in the experimental patches

From Fletcher (1987), it was clear that the removal of Centrostephanus rodgersii would lead to an increase in the abundance of foliose algae. For the purposes of this experiment, all species of foliose algae were combined into the category 'foliose algae' This category included the brown algae Ecklonia radiata, Sargassum spp., Zonaria spp., Lobophora spp., red alga Delisea pulchra and articulated coralline algae Amphiroa sp. and Corallina sp. Species of filamentous algae were also combined (see Andrew \& Underwood 1989, Underwood et al.1991) as were crustose corallines Lithothamnion sp., Neogoniolithon sp. and Porolithon sp. Differences among replicates in the species composition of these categories are highlighted where appropriate.

The numerical responses of the following variables were estimated bimonthly between September 1985 and March 1987: the percentage cover of crustose, filamentous and foliose algae (primary cover only), the density of Sargassum spp., the density of limpets (Cellana tramoserica, Patelloida alticostata and $P$. mufria) and the area of the manipulated patches of Barrens habitat. The percentage cover of algae was estimated by intersection with 100 points in 5 haphazardly tossed $0.25 \mathrm{~m}^{2}$ quadrats per patch per sample. The abundance of the small limpet $P$. mufria was also estimated within the $0.25 \mathrm{~m}^{2}$ quadrats. The densities of the limpets $P$. alticostata and C. tramoserica were estimated as counts per patch and combined because of uncertainties in identification of small individuals.

Differences among treatments in the density of Patelloida mufria at the start and end of the experiment were analysed using 2-factor nested analyses of variance (Density and Patches within each Density). Mean abundances of foliose, filamentous and crustose algae were analysed using the same design, at the end of the experiment. The mean areas of the patches and the combined abundance of $P$. alticostata and Cellana tramoserica were analysed by 1 -factor (Density) analyses of variance, which are presented in the text. Data were transformed as required (Snedecor \& Cochran 1981) and transformations are indicated where appropriate. Means were separated after significant $F$-tests by SNK tests, the results of which are reported in the text where there were unambiguous differences among means, otherwise they are presented in tables. Means reported in the text are accompanied by Standard Errors, SE ( $n=20$, pooled among patches). 
As the experiment progressed, the cover of crustose corallines significantly declined in all areas where urchins were reduced in number. In the Control, $66 \%$ and $33 \%$ treatments, the boundaries of the original patches were always clear. In the Removal treatment, the patches became blurred with the surrounding habitat. The potential therefore existed that quadrats could be sampled outside the area of the original patch. We are confident that this did not occur because, by the time the boundaries blurred, we were familiar with all the patches and sampled only within the original boundary.

The area of each patch was estimated using a modification of the technique described by Underwood (1977). One end of each of 2 tape measures was fixed a known distance apart and the intersection between the 2 tapes plotted around the outer perimeter of the areas covered by crustose coralline algae. These coordinates were then used to calculate the area of the patch. Collection of data was made logistically possible by using an underwater microphone and cassette recorder. The areas of the patches were estimated 4 times, in September 1985, March 1986, September 1986 and March 1987. Changes in area of each patch are presented as percentage of original size. Sizes of patches from the Removal treatment were not estimated because non-crustose algae colonized the entire areas of the original patches, which meant that reliable estimates of area could not be made. In addition to the experimental patches, the sizes of 29 naturally occurring patches and the numbers of Centrostephanus rodgersii in them were estimated in July 1987. The patches used in this experiment and in the sample of unmanipulated patches were chosen because they were relatively 2 -dimensional. The vertical surfaces in these patches were a small proportion of the total area. We assume no bias among treatments caused by differences in 3-dimensional complexity

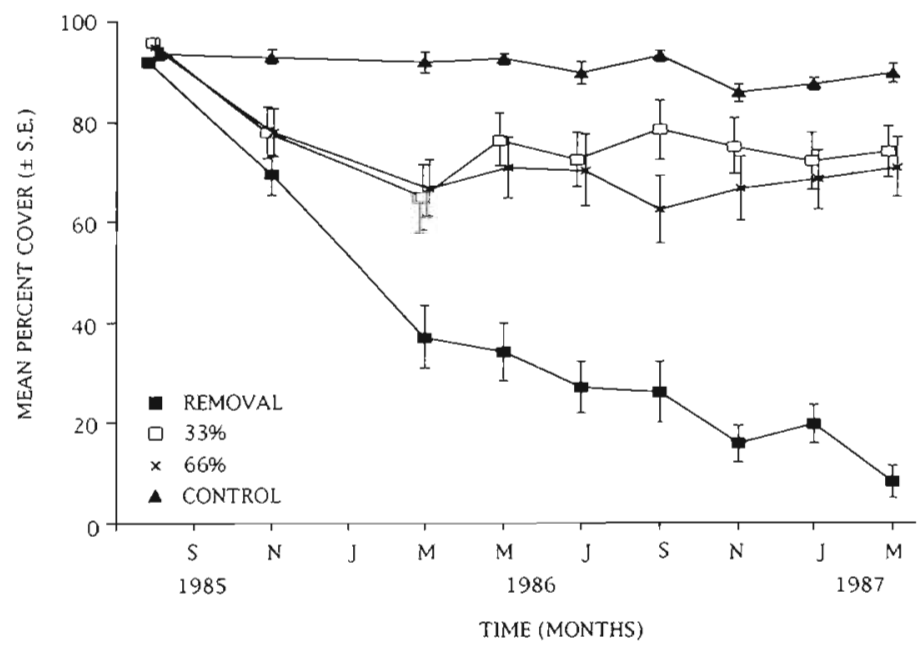

Fig. 1. Mean combined percentage cover of crustose coralline algae (all species) per $0.25 \mathrm{~m}^{2}$ in experimental treatments as a function of time. See graph for symbols. Data pooled across patches, $n=20$

\section{RESULTS}

The percentage cover of crustose coralline algae (all species) declined in patches from which all large Centrostephanus rodgersii had been removed (Fig. 1). At the end of the experiment, the combined cover of crustose algae within patches in the Removal treatment had fallen to $8.3 \%( \pm 3.07)$. This was significantly smaller than in patches that retained their full complement of sea urchins and those in which there had been a partial removal of $C$. rodgersii (Table $1 \mathrm{a}, \mathrm{c}$ ). Crustose corallines in the Control treatment remained abundant (mean $>85 \%$ ) throughout the experiment (Fig. 1).

Partial removal of Centrostephanus rodgersii caused a reduction in percentage cover of crustose corallines to approximately $70 \%$ of their original cover by March 1986. Following this initial decline, the abundance of crustose corallines in the partial removals remained relatively constant for the remainder of the experiment (Fig. 1). In March 1987, the mean percentage cover of

Table 1. Analysis of variance tables for differences among means in the percentage cover of (a) crustose corallines (all species) and (b) filamentous algae. NS = non significant, ${ }^{*} p<0.05, \cdots p<0.01$. Raw data used in both analyses. (c) SNK tests on means from the analysis of differences in crustose coralline algae among Density treatments. Treatments sharing an underline were not significantly different

\begin{tabular}{|c|c|c|c|c|c|c|c|c|}
\hline \multirow[b]{2}{*}{ Source } & \multirow[b]{2}{*}{ df for $F$} & \multicolumn{4}{|c|}{ (a) Crustose corallines } & \multicolumn{3}{|c|}{ (b) Filamentous algae } \\
\hline & & & MS & $F$ & $\mathrm{p}$ & MS & $F$ & $\mathrm{p}$ \\
\hline Density & 3,12 & & 25431.8 & 34.32 & $\cdots$ & 4809.7 & 2.72 & NS \\
\hline Patch $_{(D)}$ & 12,64 & & 741.1 & 2.49 & $\cdot$ & 1770.2 & 5.93 & $\cdots$ \\
\hline \multirow[t]{2}{*}{ Residual } & & & 298.0 & & & 298.6 & & \\
\hline & (c) Control & $33 \%$ & $66 \%$ & Removal & & & & \\
\hline
\end{tabular}




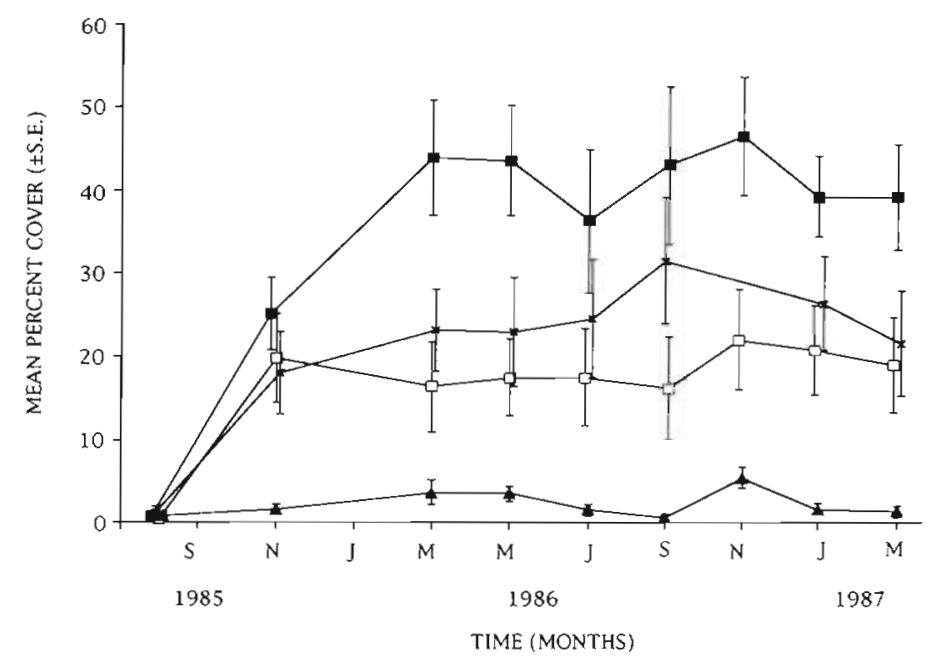

Fig. 2. Mean percentage cover of filamentous algae per $0.25 \mathrm{~m}^{2}$ in experimental treatments as a function of time. Data pooled across patches, $n=20$. Symbols as in Fig. 1 filamentous algae remained similar for the remainder of the experiment. In the Removal treatment at the end of the experiment, filamentous algae covered a mean of $39.2 \%( \pm 6.42)$ of the substratum of the original patches.

Partial removal of Centrostephanus rodgersii also caused an initially rapid increase in the cover of filamentous algae and then a more gradual net increase in mean cover over the next 16 mo (Fig. 2 ). There was considerable variance among replicate patches in the percentage cover of filamentous algae throughout the experiment. When analysed, in March 1987, differences among patches were significant (Table 1 b) and sufficiently large to swamp differences among treatments (Table 1b). In March 1987, the mean cover offilamentous algae in the $33 \%$ treatment was $19.0 \%( \pm 5.75)$ and in the $66 \%$ treatment it covered $21.6 \%$ ( \pm 6.39 ) of the substratum. The mean cover of filamentous algae in the Control crustose coralline algae was similar in the $33 \%$ and $66 \%$ treatments $(74.1 \pm 5.09$ and $71.0 \pm 5.85$ respectively). These means were not significantly different (Table 1a,c) and neither was significantly smaller than the Control mean (Table 1c).

The effects of removing all, some or no large Centrostephanus rodgersii on the percentage cover of filamentous algae (Fig. 2) were complementary to those patterns described for crustose algae (Fig. 1). In Control patches, the cover of filamentous algae was small throughout the experiment. Only once, in November 1986, did the mean cover of these species rise above $5 \%(5.4 \pm$ 1.28). There was a rapid increase in the abundance of filamentous algae following the removal of all large C. rodgersii. After 3 mo, the cover of filamentous algae had risen to $25.1 \%( \pm 4.37$ ). The rate of increase then slowed and the cover of

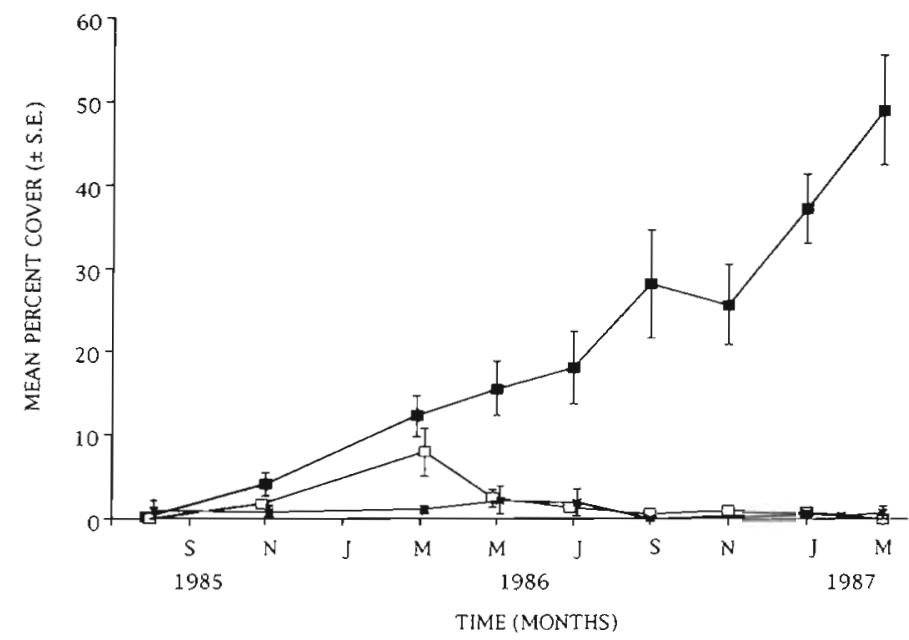

Fig. 3. Mean percentage cover of foliose algae per $0.25 \mathrm{~m}^{2}$ in experimental treatments as a function of time. Data pooled across patches, $n=20$. Symbols as in Fig. 1

Table 2. Patelloida mufria. Analysis of variance tables for differences among means in density at (a) the beginning of the experiment and (b) the end, in March 1987. NS $=$ non significant, $\cdots p<0.01$. Transformations as indicated. (c) SNK tests on. means from the analysis of differences in density among Density treatments at the end of the experiment. Treatments sharing an underline were not significantly different

\begin{tabular}{|c|c|c|c|c|c|c|c|c|}
\hline \multirow[b]{2}{*}{ Source } & \multicolumn{5}{|c|}{ (a) Beginning } & \multicolumn{3}{|c|}{ (b) End } \\
\hline & df for $F$ & & MS & $F^{3}$ & $\mathrm{p}$ & MS & $F$ & $\mathrm{p}$ \\
\hline Density & 3,12 & & 2918 & 0.94 & NS & 180.27 & 12.91 & $\cdots$ \\
\hline Patch., & 12,64 & & 3116 & 35.41 & $\cdots$ & 13.96 & 6.58 & $\cdots$ \\
\hline Residual & & & 88 & & & 2.12 & & \\
\hline Transformation & & & None & & & Square root & & \\
\hline (c) Control & & $66 \%$ & $33 \%$ & Rem & & & & \\
\hline
\end{tabular}




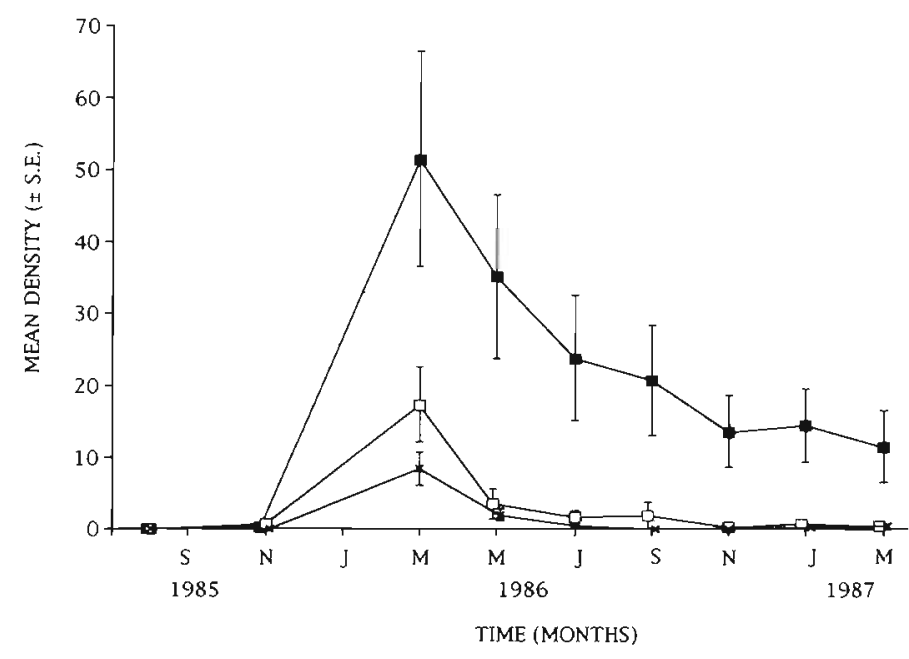

Fig. 4. Mean density of Sargassum spp. per $0.25 \mathrm{~m}^{2}$ in experimental treatments as a function of time. Data pooled across patches, $n=20$. Symbols as in Fig. 1

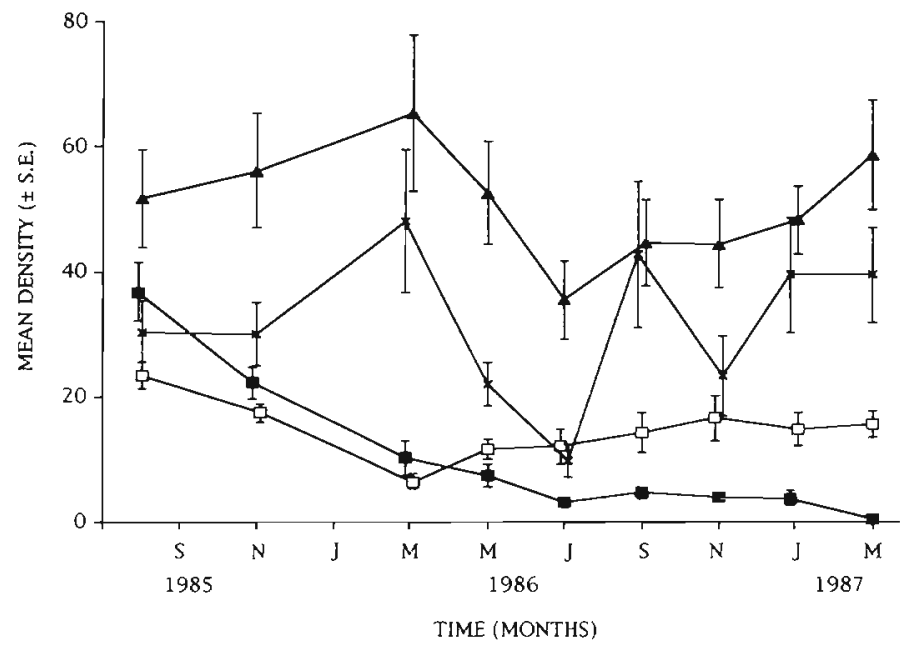

Fig. 5. Mean density of Patelloida mufria per $0.25 \mathrm{~m}^{2}$ in experimental treatments as a function of time. Data pooled across patches, $n=20$. Symbols as in Fig. 1

treatment was considerably smaller than in any other treatment (Fig. 2).

The removal of all large Centrostephanus rodgersii caused an increase in the percentage cover of foliose algae (Fig. 3). At the end of the 18 mo experimental period, foliose algae covered a mean of $49.1 \%$ ( \pm 6.59 ) of the substratum but never covered more than $5 \%$ of the substratum in the $33 \%, 66 \%$ and Control treatments (Fig. 3). The species composition of foliose algae differed greatly among patches in the Removal treatment. Fucoid and laminarian algae successfully colonized only one of the patches from which all large $C$. rodgersii had been removed. In this patch, Sargassum spp. reached a mean density of 46 per $0.25 \mathrm{~m}^{2}( \pm 8.41$ ) in March 1986, but subsequently declined (Fig. 4). In the other 3 patches, articulated coralline algae, either Amphiroa sp. or Corallina sp., predominated. The coverage of these latter species differed markedly among patches and, in general, Amphiroa sp. was abundant when Corallina sp. was not. Moreover, Sargassum spp. were not present in those patches in which Amphiroa sp. was abundant. Other foliose algae such as Ecklonia radiata, Zonaria spp. and Delisea pulchra were rare in all patches.

Sargassum spp. also recruited to patches with partial removals of sea urchins and were abundant in both $33 \%$ and $66 \%$ treatments in March 1986 (Fig. 4). Densities declined thereafter and Sargassum spp. were either rare or absent from patches at the end of the experiment. No Sargassum spp. were recorded in Control patches.

Densities of Patelloida mufria did not differ significantly among treatments at the start of the experiment (Table 2a) but, by March 1987, treatments had diverged and there were significant differences among treatments (Table 2b). The density of $P$. mufria in the Removal treatment had fallen to 0.5 per $0.25 \mathrm{~m}^{2}( \pm 0.29, \mathrm{n}=20)$ at the end of the experiment (Fig. 5). This density was significantly less than found in treatments in which some or all Centrostephanus rodgersii remained (Table $2 \mathrm{~b}, \mathrm{c}$ ). These latter treatments were not significantly different (Table 2b,c). There were significant differences in the percentage cover of filamentous algae among patches within treatments both at the beginning and end of the experiment (Table $2 a, b$ ).

The numerical responses of the limpets Patelloida alticostata/Cellana tramoserica to changes in the density of Centrostephanus rodgersii were complex and all estimates of mean density were subject to considerable variability. To simplify interpretation, absolute densities were converted to a percentage of original density. The removal of all $C$. rodgersii from patches caused a gradual decline in the density of limpets until, in March 1987 , only $6.7 \%$ ( \pm 5.8 ) of the original densities remained. There was little net change in the density of $P$. alticostata/C. tramoserica in the Control patches (Fig. 6). Analysis of differences among treatments in March 1987 indicated that the removal of all C. rodgersii caused a significant reduction in the abundance of $P$. alticostata/C. tramoserica $\left(F_{(3,12)}=57.20, p<0.001\right.$, $\log (x+1)$ transformed, SNK tests). There were no significant differences among the $33 \%, 66 \%$ and Control treatments (SNK tests). In all treatments, except $33 \%$, there was an increase in the mean density of these limpets between September and November 1986 (Fig. 6). 


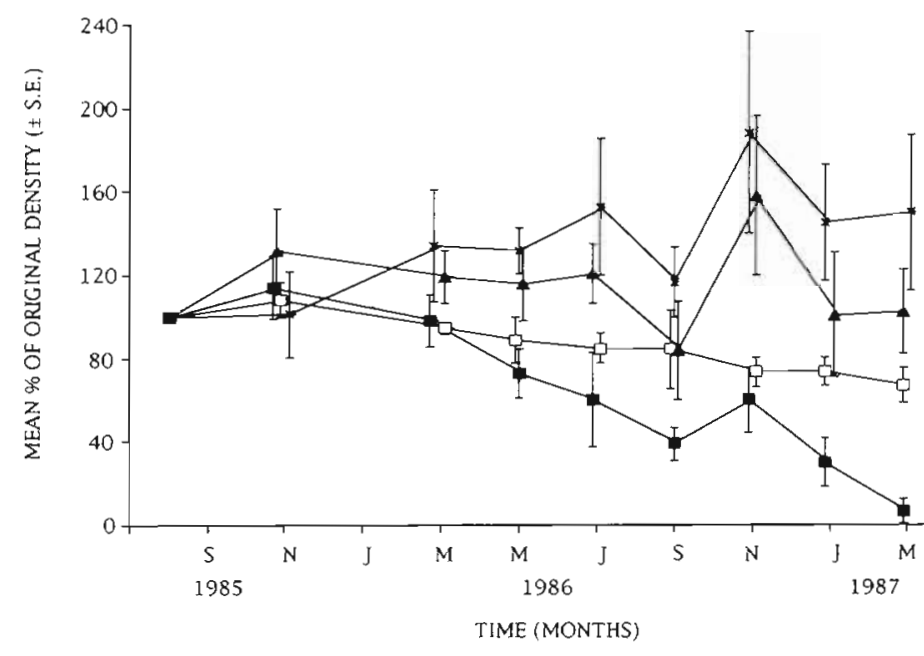

Fig. 6. Mean combined density of Patelloida alticostata and Cellana tramoserica per patch as a percentage of their density at the beginning of the experiment. Data are counts per patch $(n=4)$ as a function of time. Symbols as in Fig. 1

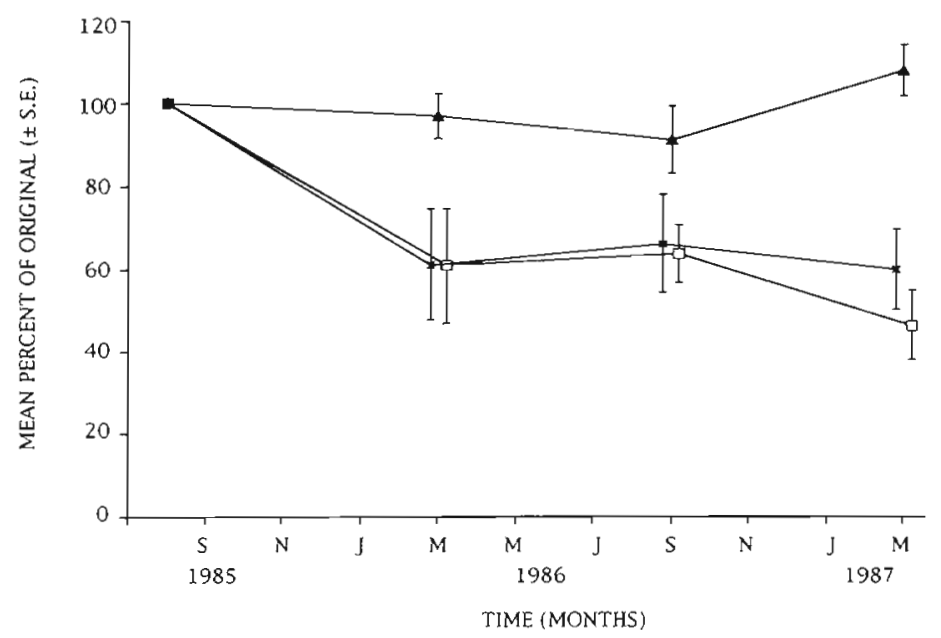

Fig. 7. Mean area of experimental patches as a percentage of their original size as a function of time. Data presented for Control, $66 \%$ and $33 \%$ treatments only. Symbols as in Fig. 1

This increase was caused by large numbers of juvenile limpets (particularly $P$. alticostata) in these samples (N.L.A. pers. obs.).

During the first 6 mo of the experiment, patches from which some or all Centrostephanus rodgersii were removed became smaller (Fig. 7). In patches that retained some sea urchins, the area of the patch was always clearly identifiable; the remaining $C$. rodgersil maintained discrete areas of the patch free of noncrustose algae. The rate at which these patches became smaller slowed in March 1986 and the average size of patches decreased only slightly thereafter (Fig. 7). In March 1987 the patches in the 33\% and $66 \%$ treatments were, on average, $46.3 \%( \pm 8.37)$ and $59.7 \%( \pm 9.74)$, respectively, of their original sizes prior to the experiment. These 2 means were not significantly different, but both were significantly smaller than the Control mean $\left(F_{12,9}\right.$ $=15.55, \mathrm{p}<0.01$, SNK tests). The mean size of patches from which no $C$. rodgersii had been removed changed little over the course of the experiment and, at the end of the experiment, were $7.9 \%( \pm 4.19)$ larger than at the start (Fig. 7).

Natural patches occurred in a range of sizes and shapes (Fig. 8A). These range from very small, almost circular areas surrounding a crevice sheltering a single sea urchin to large, highly convoluted patches containing thousands of Centrostephanus rodgersii. There was a positive correlation between the number of sea urchins in a patch and the area of the patch ( $\mathrm{r}=0.94$, $\mathrm{p}<0.01, \mathrm{n}=29$, Fig. 8B) and between number of urchins and the length of the outer perimeter of the patch $(r=0.83, p<0.01$, Fig. $8 \mathrm{C})$. When the final sizes and shapes of the experimental patches used in the experiment were compared to these general relationships, it appears that neither area nor perimeter were very similar to natural patches (Figs 8B,C). There was, however, nothing unusual about the relationship between area and perimeter in these experimental patches with respect to natural patches (Fig. 8A). When area and perimeter are considered together as a descriptor of the shape of patches, the experimental patches were within the range of variability observed in the natural patches.

\section{DISCUSSION}

In this study we have presented further evidence that Centrostephanus rodgersii is an important herbivore on shallow subtidal systems in New South Wales (Fletcher 1987, Andrew \& Underwood 1989, Andrew 1991, 1993, Underwood et al. 1991), Removal of all large $C$. rodgersii caused changes in the composition of algae and associated invertebrate herbivores. Principally, these involved the loss of crustose algae and limpets from areas of reef and the development of assemblages of filamentous and foliose algae. The result is similar to that gained in studies that have experimentally removed sea urchins from temperate reefs in other regions (see references in 'Introduction').

In common with Fletcher's (1987) study, the composition of the assemblages of foliose algae that developed in the absence of large Centrostephanus rodgersii differed among replicates. In the present study. 

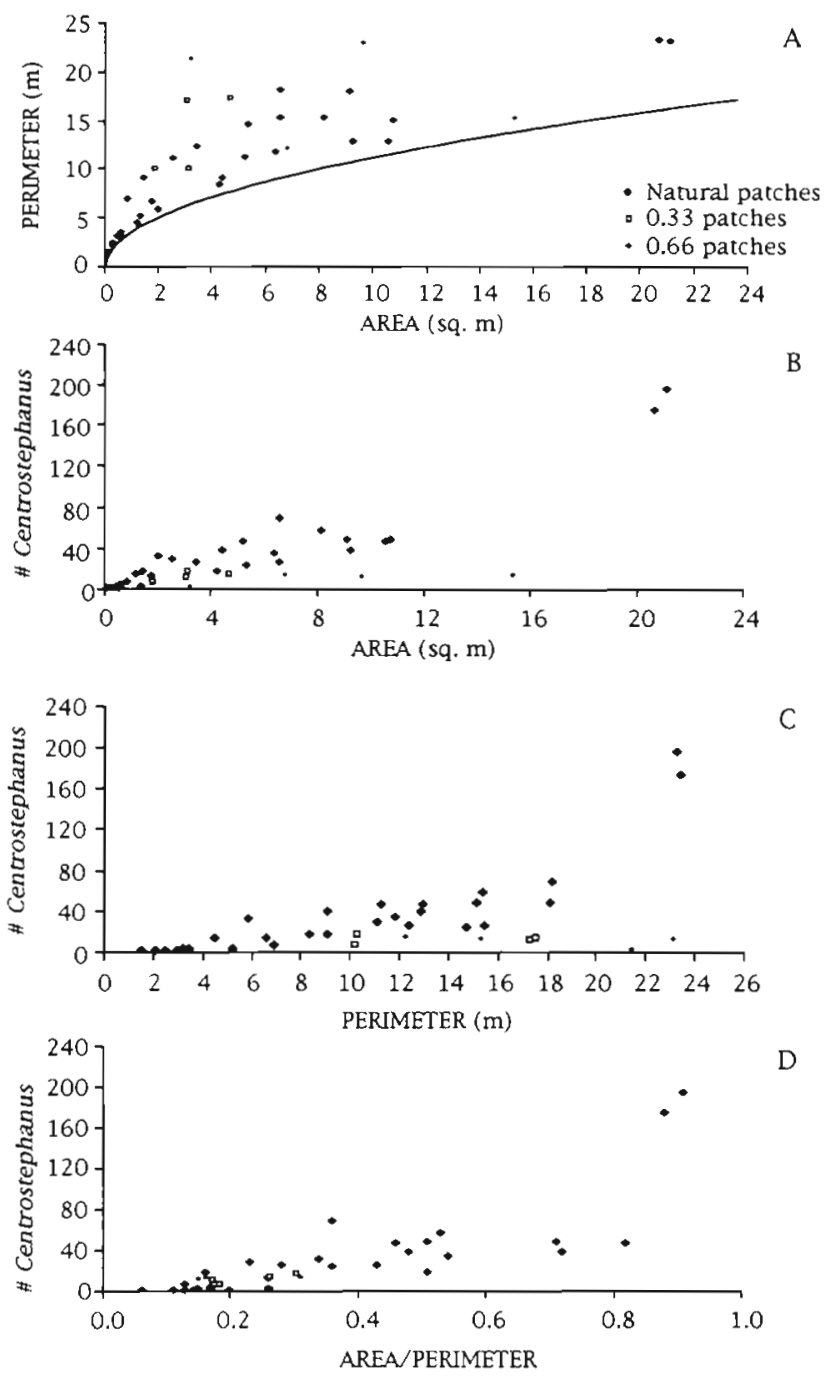

Fig. 8. Correlations between selected attributes of experimental patches and a sample $(n=29)$ of natural patches of varying sizes and shapes. (A) Perimeter vs Area. The solid line indicates the minimal relationship, that for a circle. (B) Number of Centrostephanus vs Area. (C) Number of Centrostephanus vs Perimeter (D) Number of Centrostephanus vs Area/Perimeter. See panel A for symbols

Sargassum spp. dominated some experimental patches but were absent from others in which articulated corallines were most abundant. The laminarian alga Ecklonia radiata, which is abundant in many areas in New South Wales (Underwood et al. 1991), did not colonize any of the experimental patches. The timing of the experiment cannot, however, completely explain this absence because the experiment started in August, during the recruitment season for E. radiata. In previous studies, clearances within forests during spring have produced heavy recruitment of E. radiata (e.g. Kennelly 1987, Andrew \& Jones 1990). Two possible explanations for the failure of E. radiata to colo- nize in the present study are that the patches were too far from sources of spores and/or the remaining limpets in the patches in the first season removed newly settled plants. There is no way to discriminate between these 2 interpretations from the present experiment.

Beyond the added generality this study provides to the results of previous removal experiments, we have demonstrated that, even at reduced densities, Centrostephanus rodgersii is able to maintain areas of reef free of foliose algae. Further, we have demonstrated that sea urchins greater than $50 \mathrm{~mm}$ TD account for the great majority of grazing pressure in the Barrens habitat. Foliose algae successfully colonized the Removal treatments despite the presence of small C. rodgersii. Although Sargassum recruited to patches in these treatments in the austral summer 1986-87, these plants subsequently disappeared, suggesting that either the remaining sea urchins grazed over these previously grazed areas, or recruit Sargassum were outcompeted by the filamentous algae that predominated in these zones. Evidence against the latter alternative comes from the successful colonization and persistence of foliose species in the Removal treatment, despite comparable cover of filamentous algae (see also Fletcher 1987, Andrew 1991).

There was considerable non-linearity in the response of many variables to the reductions in the density of Centrostephanus rodgersii. The numerical responses of crustose corallines, filamentous algae, foliose algae and limpets were all similar whether $33 \%$ or $66 \%$ of $C$. rodgersii were removed. Although the reasons underlying this non-linearity are unclear, the results suggest that there were compensatory changes in the foraging behaviour of individual sea urchins and that foliose algae were the most susceptible to grazing. Further experimentation is needed to determine whether the sea urchins consume species of foliose algae selectively, or whether the observed pattern is due to the faster rates of growth and recruitment of the filamentous species.

An alternative explanation for the observed non-linearities is that intra-patch differences in densities of limpets and small sea urchins (<50 mm TD) were sufficiently large to cancel out differences among treatments. In March 1987, at the end of the experiment, mean densities of small sea urchins were: Control, 10.8 $\pm 4.2 ; 66 \%, 6.2 \pm 0.5 ; 33 \%, 5.0 \pm 0.7$; Removal, $3.25 \pm$ 0.48 . These densities were not significantly different $\left(F_{(3,12)}=2.2\right.$, ns $)$ and could not alone account for the observed changes in the abundance of algae. Further, observed changes in the density of the limpets would have accentuated differences in the abundance of algae between the 2 partial removal treatments.

The numerical response of limpets to the removal of 


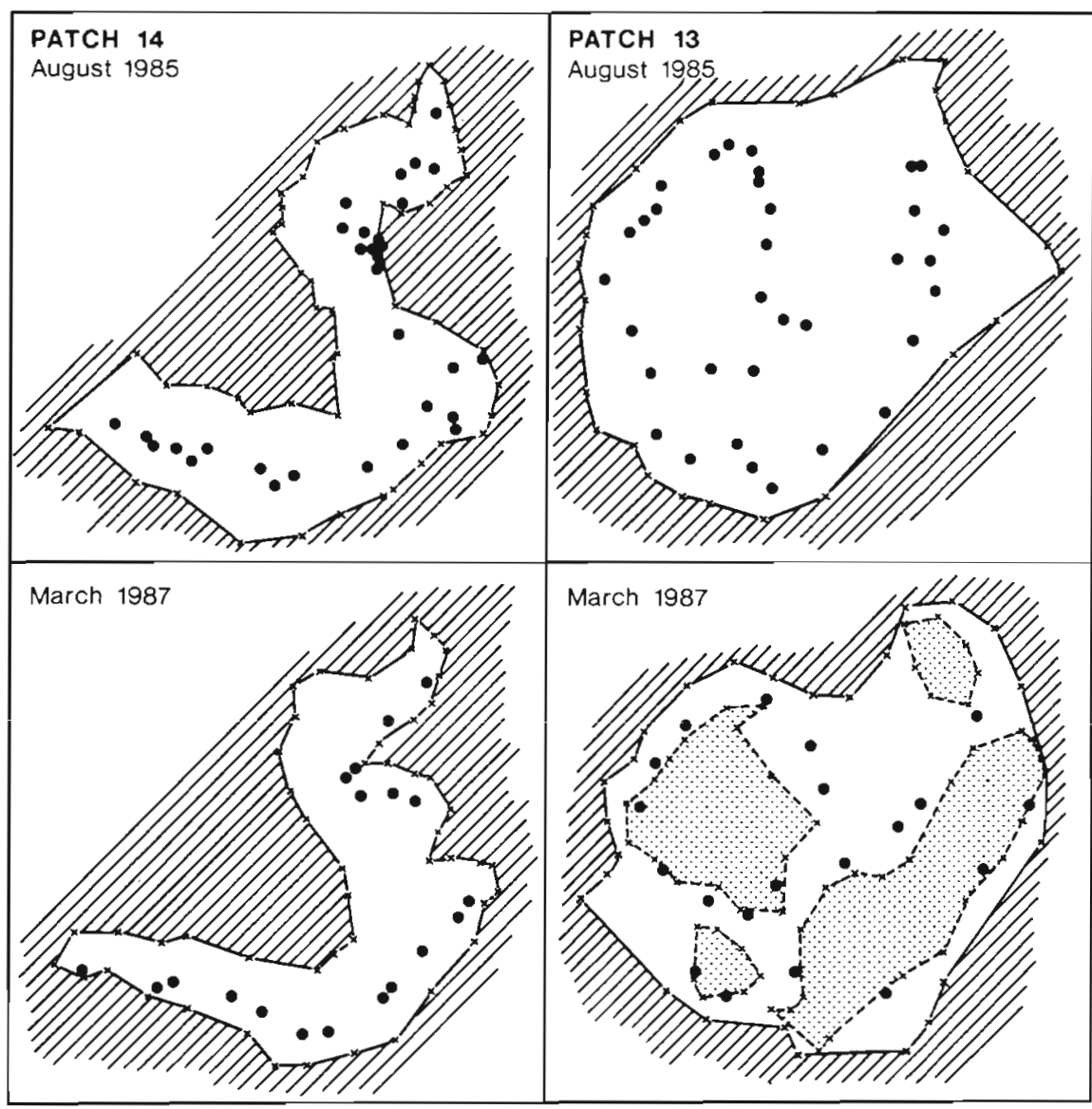

Fig. 9. Changes in the size and shape of 2 exemplary patches (\#13 and 14) at the beginning (August 1985) and end (March 1987) of the experiment. Both patches retained $66 \%$ of their complement of sea urchins. The cross-hatched areas indicate areas of foliose algae and the stippled areas in Patch 13 represent areas covered by filamentous algae. Large dots indicate the positions of sea urchins at the time of sampling

all large Centrostephanus rodgersii was similar to that described by Fletcher (1987). In both experiments, limpets all but disappeared from areas not grazed by C. rodgersii. There were, however, some differences between the 2 studies in the response of Patelloida mufria. In Fletcher's experiments, the removal of $C$. rodgersii caused a large, if short-lived, increase in the density of this small limpet. In the present experiment, although started in the same month, the density of $P$. mufria declined relatively monotonically over the course of the experiment. A possible cause for this difference lies in the relative rates of increase in the abundance of non-crustose algae between the 2 studies. In Fletcher's experiments, non-crustose algae (his foliose algae) covered less than $50 \%$ of the substratum for at least $20 \mathrm{mo}$. In contrast, in the present study, the combined cover of filamentous and foliose algae was greater than $50 \%$ after only 8 mo. Alternatively, differences in the timing and magnitude of recruitment may adequately account for discrepencies between the 2 studies.

The response of populations of Patelloida mufria to partial removals was not clear. There was evidence of seasonal variations in abundance in the $66 \%$ treatment, but not in those patches that retained $33 \%$ of large Centrostephanus rodgersii. There was no evidence of a spectacular increase in density in these treatments. This result was probably caused by the clearly zoned pattern in grazing by $C$. rodgersii. The development of discrete zones within these patches suggests that, in areas adjacent to shelters, the intensity of grazing was comparable to that prior to the manipulations, but was severely reduced outside clearly defined, new boundaries. The absence of foliose algae outside these new boundaries suggests that sea urchins occasionally grazed over these areas of substratum and removed the slower-growing foliose algae.

There was no significant difference in the percentage reduction in sizes of the patches when $33 \%$ and $66 \%$ of large sea urchins remained. We suggest that the shapes of the original patches and the sizes of the crevices within them contributed to this lack of difference. Rounded patches had more sea urchins per unit of perimeter than did longer and more narrow patches and hence individual sea urchins would have to move further to go beyond areas of heavily grazed substratum. Removal of sea urchins from more rounded patches had the effect of increasing the effective perimeter of the patch and producing a greater proportional reduction in area. Comparison of Patches 13 and 14 , both from the $66 \%$ treatment, illustrates these differences and their consequences (Fig. 9). Patch 14 suffered only an $11 \%$ reduction in area, whereas Patch 13, which was more rounded, was $47 \%$ smaller at the end of the experiment. Although treatments were randomly assigned to patches, more 'rounded' patches became $66 \%$ treatments than $33 \%$ treatments (pers. obs.).

It is well known that the size of a patch can influence the events within it, for example, the recolonization of 
disturbed patches by propagules and by vegetative extension from neighbours (e.g. Abele \& Patton 1976 , Paine \& Levin 1981, Gunnill 1982, Keough 1984, Sousa 1984, Schroeder 1987, Navarrete \& Castilla 1990, Butler 1991). The shape of patches, potentially another influence on the dynamics of species within, has been considered less often. Sousa (1985) has discussed the consequences of the shape of patches, largely within the context of external disturbances and the rate of recolonization from adjacent organisms. Small patches have a greater perimeter/area ratio than do large patches, hence there is a greater likelihood of recolonization from adjacent organisms (by extension into the patch) per unit area in a small patch than a larger one, even if they are the same shape (Sousa 1984, 1985, Navarrete \& Castilla 1990). Structural complexity, or 3 -dimensional shape, has similarly been shown to be important in influencing the recruitment of amphipods to benthic macrophytes (e.g. Schneider \& Mann 1991).

Further understanding of the importance of crevice shape in determining the size of patches of Barrens habitat will require the creation of shelters with the same area but of different shapes. Similarly, the question remains as to what would have happened if densities had been increased rather than reduced from those occurring naturally. We speculate that, in those instances in which there was sufficient shelter to accommodate more sea urchins, the area of the patch would increase, but that the per capita contribution of sea urchins to this area would be diminished as more were added. In cases where there was insufficient shelter, we predict that 'excess' individuals would be dissipated among nearby shelters or eaten by predators.

In the present study changes in the behaviour of Centrostephanus rodgersii and subsequent effects on the benthic community were of quantity rather than kind. Although not expected with a reduction in density, no $C$. rodgersii were observed to abandon their crevice-bound existence and actively forage over areas of foliose algae. In this respect, the behaviour of C. rodgersii is similar to that described for its congener C. coronatus (Vance 1979, Vance \& Schmitt 1979) and other diadematids, such as the tropical Diadema spp. (e.g. Ogden et al. 1973, Carpenter 1981, 1986).

Acknowledgements. We thank Sally McNeill for assistance in the field and Julio Arrontes for comments on the manuscript. We are grateful to Ricardo Anadón and the Departamento de Biología de Organismos y Sistemas, Universidad de Oviedo, for support during the completion of the manuscript. This study was done while N.L.A. was in receipt of a Commonwealth Scholarship and Fellowship Plan Award. Additional support was provided by the School of Biological Sciences and Institute of Marine Ecology, University of Sydney, and a grant from the Australian Research Council (to A.J.U.) for which we are grateful.

\section{LITERATURE CITED}

Abele, L. G., Patton, W. K. (1976). The size of coral heads and the community biology of associated decapod crustaceans. J. Biogeogr. 3: 35-47

Andrew, N. L. (1991). Changes in habitat structure following mass mortality of sea urchins in Botany Bay, New South Wales. Aust. J. Ecol, 16: 353-362

Andrew, N. L. (1993). Spatial heterogeneity, sea urchin grazing, and habitat structure on reefs in temperate Australia. Ecology 74: 292-302

Andrew, N. L., Choat, J. H. (1982). The influence of predation and conspecific adults on the survivorship of juvenile Evechinus chloroticus (Echinoidea: Echinometridae) Oecologia 54: 80-87

Andrew, N. L., Jones, G. P. (1990). Patch formation by herbivorous fish in a temperate Australian kelp forest. Oecologia 85: $57-68$

Andrew, N. L., Underwood, A. J. (1989). Patterns of abundance in the sea urchin Centrostephanus rodgersii on the central coast of New South Wales. J. exp. mar. Biol. Ecol. 131: $61-80$

Bernstein, B. B., Williams, B. E., Mann, K. H. (1981). The role of behavioural responses to predators in modifying urchins' (Strongylocentrotus droebachiensis) destructive grazing and seasonal foraging patterns. Mar. Biol. 63: $39-49$

Breitburg, D. L. (1985). Development of a subtidal epibenthic community: factors affecting species composition and the mechanisms of succession. Oecologia 65: 173-184

Butler, A. J. (1991). Effect of patch size on communities of sessile invertebrates in Gulf St Vincent, South Australia. J. exp. mar. Biol. Ecol. 153: 255-280

Carpenter, R. C. (1981). Grazing by Diadema antillarum (Phillippi) and its effects on benthic algal community. J. mar. Res. 39: 749-765

Carpenter, R. C. (1986). Partitioning herbivory and its effects on coral reef algal communities. Ecol. Monogr. 56: $345-363$

Chapman, A. R. O. (1981). Stability of urchin dominated barren grounds following destructive grazing of kelp in St. Margarets Bay, eastern Canada. Mar Biol. 62: $307-311$

Cowen, R. K., Agegian, C. R., Foster, M. S. (1982). The maintenance of community structure in a central California giant kelp forest. J. exp. mar. Biol. Ecol. 64: 189-201

Dayton, P. K. (1975). Experimental studies of algal canopy interactions in a sea otter-dominated kelp community at Amchitka Island, Alaska. Fish. Bull. U.S. 73: 230-237

Duggins, D. O. (1980). Kelp beds and sea otters: an experimental approach. Ecology 61: 447-453

Duggins, D. O. (1983). Starfish predation and the creation of mosaic patterns in a kelp-dominated community. Ecology 64: $1610-1619$

Ebert, T. A. (1977), An experimental analysis of sea urchin dynamics and community interactions on a rock jetty. J. exp. mar. Biol. Ecol. 27: 1-22

Elner, R. W., Vadas, R. L. (1990). Inference in ecology - the sea urchin phenomenon in the northwestern Atlantic. Am. Nat. 136: 108-125

Estes, J. A., Palmisano, J. F. (1974). Sea otters: their role in structuring nearshore communities. Science 185 $1058-1060$

Fletcher, W. J. (1987). Interactions among Australian sea urchins, gastropods, and algae: effects of experimental removals. Ecol. Monogr. 57: 89-109

Forster, G. R. (1959). The ecology of Echinus esculentus L 
Quantitative distribution and rate of feeding. J. mar. biol. Ass. U.K. 38: 361-367

Gunnill, F. C. (1982). Effects of plant size and distribution on the numbers of invertebrate species and individuals inhabiting the brown alga Pelvetia fastigiata. Mar. Biol. 69 : $263-280$

Harrold, C., Reed, D. C. (1985). Food availability, sea urchin grazing, and kelp forest community structure. Ecology 66: $1160-1169$

Hay, M. E., Taylor, P. R. (1985). Competition between herbivorous fishes and urchins on Caribbean reefs. Oecologia 65: $591-598$

Himmelman, J. H., Cardinal, A., Bourget, E. (1983). Community development following removal of urchins, Strongylocentrotus droebachiensis, from the rocky subtidal zone of the St. Lawrence estuary, eastern Canada. Oecologia 59: 27-39

Jones, G. P., Andrew, N. L. (1990). Herbivory and patch dynamics on rocky reefs in temperate Australasia: the roles of fish and sea urchins. Aust. J. Ecol. 15: 505-520

Kennelly, S. J. (1987). Inhibition of kelp recruitment by turfing algae and consequences for an Australian kelp community. J. exp. mar. Biol.Ecol. 112: 49-60

Keough, M. J. (1984). Effects of patch size on the abundance of sessile marine invertebrates. Ecology $65 ; 423-437$

Kitching, J. A., Ebling, F. J. (1961). The ecology of Lough Ine. XI. The control of algae by Paracentrotus lividus (Echinoidea). J. Anim. Ecol. 30: 373-383

Mattison, J. E., Trent, J. D., Shanks, A. L., Akin, T. B., Pearse, J. S. (1977). Movement and feeding activity of red sea urchins (Strongylocentrotus franciscanus) adjacent to a kelp forest. Mar. Biol. 39: 25-30

Moreno, C. A., Sutherland, J. P. (1982). Physical and biological processes in a Macrocystis pyrifera community near Valdivia, Chile. Oecologia 55: 1-6

Navarrete, S. A., Castilla, J. C. (1990). Barnacle walls as mediators of intertidal mussel recruitment: effects of patch size on the utilization of space. Mar. Ecol. Prog. Ser. 68: $113-119$

Ogden, J. C., Brown, R. A., Salesky, N. (1973). Grazing by the echinoid Diadema antillarum Philippi: formation of halos around West Indian patch reef. Science 182: $715-717$

Paine, R. T., Levin, S. A. (1981). Intertidal landscapes: disturbance and the dynamics of pattern. Ecol. Monogr. 51 . $145-178$

Sammarco, P. W. (1980). Diadema and its relationship to coral spat mortality: grazing, competition, and biological disturbance. J. exp. mar. Biol. Ecol. 45: 245-272

Santelices, B., Ojeda, F. P. (1984). Population dynamics of coastal forests of Macrocystis pyrifera in Puerto Toro, Navarino Island, southern Chile. Mar. Ecol. Prog. Ser. 14: $175-183$

Scheibling, R. E., Hamm, J (1991). Interactions between sea urchins (Strongylocentrotus droebachiensis) and their predators in field and laboratory experiments. Mar. Biol 110: $105-116$

Schneider, F. I., Mann, K. H. (1991). Species specific relationships of invertebrates to vegetation in a seagrass bed. II. Experiments on the importance of macrophyte shape, epiphyte cover and predation. J. exp. mar. Biol. Ecol. 145: 119-139

Schroeder, R. E. (1987). Effects of patch reef size and isolation on coral reef fish recruitment. Bull. mar. Sci. 41: 441-451

Snedecor, G. W., Cochran, W. G. (1981). Statistical methods, 7 th edn. Iowa State University Press, Ames

Sousa, W. P. (1984). Intertidal mosaics: patch size, propagule availability, and spatially variable patterns of succession Ecology 65: 1918-1935

Sousa, W. P. (1985). Disturbance and patch dynamics on rocky intertidal shores. In: Pickett, S. T. A., White, P. S. (eds.) The ecology of natural disturbance and patch dynamics. p. $101-124$

Sousa, W. P., Schroeter, S. C., Gaines, S. D. (1981). Latitudinal variation in intertidal algal community structure: the influence of grazing and vegetative propagation. Oecologia 48: $297-307$

Tegner, M. J., Dayton, P. K. (1991). Sea urchins, El Nin̄os, and the long term stability of southern California kelp forest communities. Mar. Ecol. Prog. Ser. 77: 49-63

Underwood, A. J. (1977). Movements of intertidal gastropods. J. exp. mar. Biol. Ecol. 26: 191-201

Underwood, A. J., Kingsford, M. J., Andrew, N. L. (1991). Patterns in shallow subtidal marine assemblages along the coast of New South Wales. Aust. J. Ecol. 16: $231-249$

Vadas, R. L., Elner, R. W., Garwood, P. E., Babb, I. G. (1986). Experimental evaluation of aggregation behaviour in the sea urchin Strongylacentrotus droebachiensis. A reinterpretation. Mar. Biol. 90: 433-448

Valentine, J. F., Heck, K. L. (1991). The role of sea urchin grazing in regulating subtropical seagrass meadows: evidence from field manipulations in the northern Gulf of Mexico. J. exp. mar. Biol. Ecol. 154: 215-230

Vance, R. R. (1979). Effects of grazing by the sea urchin, Centrostephanus coronatus, on prey community composition. Ecology 60: 537-546

Vance, R. R, Schmitt, R. J. (1979). The effect of predatoravoidance behaviour of the sea urchin Centrostephanus coronatus, on the breadth of its diet. Oecologia 44: $21-25$

Watanabe. J. M., Harrold, C. (1991). Destructive grazing by sea urchins Strongylocentrotus spp in a central California kelp forest - potential roles of recruitment, depth, and predation. Mar. Ecol. Prog. Ser. 71: 125-141

Witman, J. D. (1987). Subtidal coexistance: storms, grazing, mutualism, and the zonation of kelps and mussels. Ecol. Monogr. 57: 167-187

Manuscript first received: August 19, 1992 Revised version accepted: March 16, 1993 